\title{
Gingival Crevicular Blood Glucose Evaluation in Patients with Periodontitis: Evolution of A New Screening Technique
}

Quratulain Saeed ${ }^{1}$

Sarwat Memon ${ }^{2}$

Mervyn Hosein ${ }^{3}$
BDS

BDS, FCPS

BDS, FDSRCS, FDSRCSEd, FFDRCSI

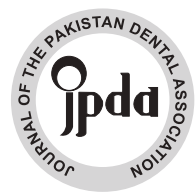

OBJECTIVE: The aim and objective of this study was to assess if gingival crevicular blood could be utilized for blood glucose evaluation in patients with periodontitis and to check the reliability of this screening method.

METHODOLOGY: The study was conducted at the department of Oral Medicine, Ziauddin Dental Hospital, Karachi. The sample size involved 348 participants with chronic periodontitis. The gingival crevicular blood produced during periodontal probing was collected on a glucometer strip to assess random glucose levels. Glycemic levels were also checked by finger capillary blood via a glucometer. Intravenous blood glycated hemoglobin A1c test was performed in patients found with blood glucose levels in pre-diabetic or diabetic range.

RESULTS: The results of this study demonstrate a strong correlation $(0.987, \mathrm{p}<0.001)$ between gingival crevicular blood and finger capillary blood glucose values and good correlation $(0.709, \mathrm{p}<0.001)$ between gingival crevicular bloodglucose and glycated Hemoglobin A1c levels. Receiver operating characteristic curve showed $94.1 \%$ sensitivity and $100 \%$ specificity of GCB glucose screening at the cut-off value of $168 \mathrm{mg} / \mathrm{dl}$. Gingival crevicular blood glucose showed significant regression with Finger capillary bloodglucose $\left(\mathrm{R}=0.987, \mathrm{R}^{2}=0.974, \mathrm{p}<0.001\right)$ andglycated hemoglobin $A 1$ clevels $\left(\mathrm{R}=0.709, \mathrm{R}^{2}=0.502, \mathrm{p}<0.001\right)$. CONCLUSIONS: From this study we conclude that gingival crevicular blood can be relied upon for screening of blood glucose levels in periodontitis patients presenting with bleeding on probing.

KEYWORDS: Blood glucose, Diabetes Mellitus, Gingival Crevicular blood,Inflammation, Periodontitis.

HOW TO CITE: Saeed Q, Memon S, Hosein M. Gingival crevicular blood glucose evoluation in patients with periodontitis: Evolution of a new screening technique. J Pak Dent Assoc 2020;29(4):193-198.

DOI: https://doi.org/10.25301/JPDA.294.193

Received: 29 March 2020, Accepted: 22 June 2020

\section{INTRODUCTION}

$\mathrm{D}$ iabetes mellitus and periodontitis are two common chronic pathologies. It is commonly acknowledged that there exists a two-way association between diabetes mellitus and periodontitis and the presence of one disease increases the severity of the other. Diabetes is perceived as a significant risk factor for periodontitis. It has been proven that people with diabetes are more vulnerable to periodontal diseases as compared to people without diabetes. ${ }^{1}$ Periodontal inflammation with diabetes mellitus can cause aesthetic and functional disturbances in teeth and increase the chances of periodontal pocket formation and alveolar bone resorption. ${ }^{2}$ Diabetes is more prevalent in the

1. M.Phil. Trainee, Department of Oral Biology, Ziauddin College of Dentistry, Ziauddin University, Karachi, Pakistan.

2. Associate Professor, Department of Orthodontics, Ziauddin College of Dentistry, Ziauddin University, Karachi, Pakistan.

3. Professor, Principal, Ziauddin College of Dentistry, Ziauddin University, Karachi, Pakistan.

Corresponding author: "Dr. Quratulain Saeed" < ainysaeed.aidm@ gmail.com > developing countries, where around $46 \%$ of all the cases are estimated to be undiscovered. ${ }^{3}$ In Pakistan, the prevalence of diabetes is more than $11 \%$. Uncontrolled diabetes can increase the mortality rate of the affected population. Diabetic complications accounted for the death of 5 million individuals in Pakistan in 2015. ${ }^{4}$ Most of the persons diagnosed with diabetes fail to keep up with their routine checkups and evaluation of glycemic control. Uncontrolled diabetes causes both micro-vascular and macro-vascular complexities. Significant complications of diabetes include retinopathy, neuropathy, cardiovascular disorders, nephropathy, cerebrovascular diseases and delayed wound healing. ${ }^{5}$ Periodontitis is an early complication of diabetes. Both diabetes and periodontal disease are pathologically linked by inflammation and chronic periodontal inflammation may give a clue to an underlying systemic disease. ${ }^{6}$

Commonly used screening tests for diabetes include evaluation of fasting plasma glucose, oral glucose tolerance tests and glycosylated hemoglobin (HbA1c) test. ${ }^{7}$ Glucose self-observing devices (glucometers) offer a straightforward 
and sensibly precise technique to screen blood glucose levels. ${ }^{8}$ Most of the currently used glucometers require small amount of blood to deliver results. ${ }^{9}{ }^{10}$ Past studies suggest that blood glucose screening via glucometers can serve as a more convenient, cost-effective and less intrusive alternate for diabetes screening as compared to conventionally used methods. ${ }^{11,12}$

Since periodontal disease may predispose individuals to incident diabetes, the dental visit offers a unique opportunity to screen an especially at-risk population. ${ }^{13}$ According to a study conducted by Rosedale et al (2012), the use of GCB was approved by the patients as a more convenient method for diabetes screening as compared to conventionally used methods. ${ }^{12}$ Although most of the past studies support the use of GCB for glucose screening as a non-invasive method but they were conducted on a smaller sample size. ${ }^{14-17}$ Moreover, there is limited literature available to prove the accuracy and reliability of this screening technique and its association with standardized $\mathrm{HbA} 1 \mathrm{c}$ test. Therefore, this study was conducted to evaluate if gingival crevicular blood could reliably be used for screening diabetes in patients with periodontitis, with the help of glucometers and to assess the accuracy of this technique as compared to finger capillary blood (FCB) glucose screening and intravenous HbA1c scores.

\section{METHODOLOGY}

This cross-sectional study was carried out for the duration of 6 months starting from 1stDecember 2018 to 30th May 2019 , among patients with periodontitis, visiting the department of Oral Medicine, Ziauddin Dental Hospital, Karachi, Pakistan. The study was approved by Research Advocacy Committee, Ethical Review Committee and Board of Advanced Studies and Research Ziauddin University, under the reference number (0450818QPOM). Open Epi Version 3.0 was used to determine the sample size of the study. The sample size of minimum 348 patients was calculated according to $34.5 \%$ prevalence of periodontitis. ${ }^{18}$ Confidence interval was taken at $95 \%$ and consecutive sampling technique was used to recruit the patients.

Both male and female patients aged 25 to 60 years of age were included in the study. The inclusion criteria were patients presenting with periodontitis $(\geq 3 \mathrm{~mm}$ clinical attachment loss) and bleeding on periodontal probing. The exclusion criteria included patients having purulent periodontal discharge, patient's presenting with a history of anemia or polycythemia, and known cases of cardiovascular, renal and hepatic disorders.

After informing the participants about the study procedure, verbal and written consent was obtained from all the patients presenting with periodontitis. The site with periodontal inflammation or bleeding was chosen for periodontal probing. For gingival crevicular blood (GCB) sample collection, preference was given to maxillary anterior teeth for the ease of isolation from salivary contamination. The isolation was maintained by cotton rolls. Periodontal probing was performed by University of North Carolina (number 15) periodontal probe and a small drop of GCB was collected directly on the glucometer strip for assessment of random blood glucose. Freestyle glucometers by Abbott Diabetes Care were used in our study.

For obtaining random finger capillary blood (FCB) glucose readings, the finger bed was cleaned with disposable alcohol wipes. A sterile lancet was used to gently prick the site and a small drop of blood was collected on the glucometer strip to produce the results. Intravenous glycated hemoglobin (HbA1c) was checked at Ziauddin Laboratory, in patients with blood glucose measurements in pre-diabetic $(180-200 \mathrm{mg} / \mathrm{dl})$ and diabetic $(>200 \mathrm{mg} / \mathrm{dl})$ range. ${ }^{19} \mathrm{HbA} 1 \mathrm{c}$ levels of $<5.7 \%$ indicated that the patient was a non-diabetic while levels between 5.7-6.4\% determined a pre-diabetic state. The diagnosis of diabetes was determined with $\mathrm{HbA} 1 \mathrm{c}$ scores of $6.5 \%$ and above. ${ }^{20}$

\section{STATISTICAL ANALYSIS OF DATA}

The data were analyzed through SPSS version 20 . Frequency and percentage were calculated for descriptive variables(gender and diabetes screening status).Mean and standard deviation was assessed for numerical variables (age, GCB and FCB glucose values). Karl Pearson formula was used to find the correlation between gingival crevicular blood glucose, finger capillary blood glucose and $\mathrm{HbA} 1 \mathrm{c}$ levels. Difference in mean between GCB and FCB glucose was calculated. ROC (receiver operating characteristic) curve was calculated to determine the sensitivity and specificity of gingival crevicular blood glucose assessment. Linear regression analysis was performed to confirm the association between GCB glucose levels and HbA1c scores.

\section{RESULTS}

A total of 348 participants took part in this study out of which 202 (58\%) were females and 146 (48\%) were males.The age range of the participants was 25 to 60 years and the mean age was 42.97 with standard deviation of 10.35 years.In our study, more than half of the overall participants $(51.1 \%)$ reported to be unaware of their glycemic status and were never screened for diabetes before; out of these 20 patients had their blood glucose levels in the diabetic range while 15 patients were found to have their blood 
glucose values in the pre-diabetic range (Figure 1). When $\mathrm{HbA} 1 \mathrm{c}$ test was performed in such patients, 17 were confirmed with diabetes (HbA1c $\geq 6.5 \%)$ and 2 patients were found to be pre-diabetics(HbA1c 5.7-6.4\%). When correlation of GCB with FSB and HbA1c was assessed, a significant positive correlation was observed (Table 1).

Figure 1

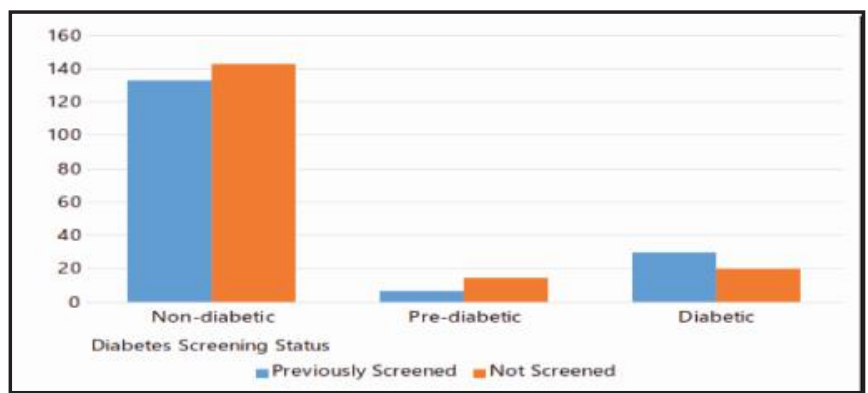

Table 1: Correlation of Gingival crevicular blood glucose levels with Finger Capillary blood glucose levels and HbA1c scores

\begin{tabular}{|c|c|c|c|c|}
\hline & & $\begin{array}{c}\text { Gingival } \\
\text { crevicular } \\
\text { blood glucose } \\
\text { readings }\end{array}$ & $\begin{array}{c}\text { Finger } \\
\text { capillary } \\
\text { blood glucose } \\
\text { readings }\end{array}$ & $\begin{array}{l}\text { HbA1c } \\
\text { score }\end{array}$ \\
\hline $\begin{array}{l}\text { Gingival } \\
\text { crevicular blood } \\
\text { glucose readings }\end{array}$ & $\begin{array}{l}\text { Pearson } \\
\text { Correlation } \\
\text { Sig. (2-tailed) } \\
\text { N }\end{array}$ & 1 & $\begin{array}{c}.987^{\star *} \\
<.0001^{\text {w* }} \\
348\end{array}$ & $\begin{array}{c}.709 \\
<.0001^{\text {ww }} \\
52\end{array}$ \\
\hline
\end{tabular}

**Correlation is significant at the 0.01 level. Less than 0.0001 represents highly significant correlation, $N=$ Sample size.

Figure 2

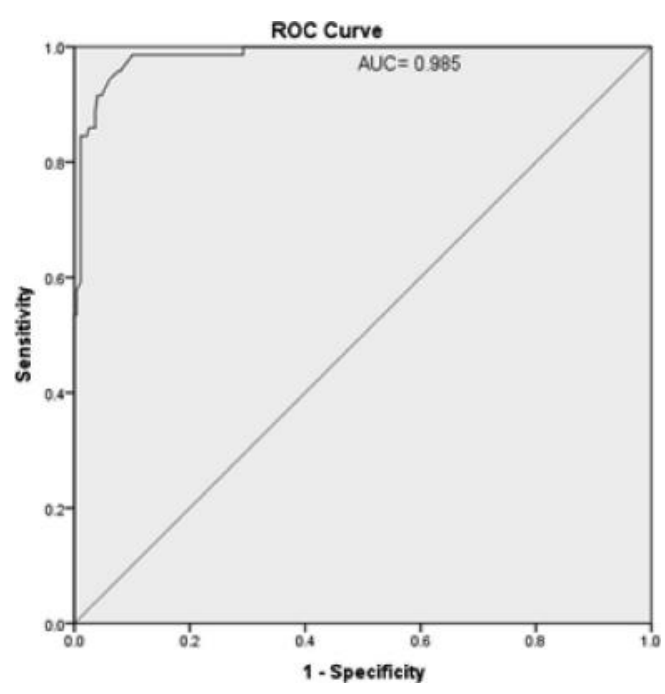

Receiver operating characteristic curve showing Area under the curve (AUC) of 0.985 (level of significance $=<0.001$, standard error $=0.006)$

The means of GCB and FCB values were found to be $151.69+/-60.48$ and 159.78+/-61.99 respectively. Difference in means of GCB and FCB was calculated by t-test which showed a mean difference of 8.09+/-10.06 (Table 2). ROC was generated to determine the sensitivity and

Table 2: Difference in mean between GCB and FCB glucose values

\begin{tabular}{|c|c|c|c|c|c|}
\hline $\begin{array}{c}\text { Mean GCBG } \\
\text { values }\end{array}$ & $\begin{array}{c}\text { Mean FCBG } \\
\text { Values }\end{array}$ & $\begin{array}{c}\text { Difference in } \\
\text { Mean }\end{array}$ & SD & $t$ & P value \\
\hline $151.69+/-60.4$ & $\begin{array}{c}159.78+/- \\
61.998348\end{array}$ & $\mathbf{8 . 0 9 2 0}$ & 10.06793 & 14.993 & $<0.0001$ \\
\hline
\end{tabular}

GCBG=Gingival Crevicular Bood glucose, $F C B G=$ Finger Capillary Blood Glucose, $S D=$ Standard Deviation, $t=t$-statistic, $P$ value $=$ Level of significance

Figure 3

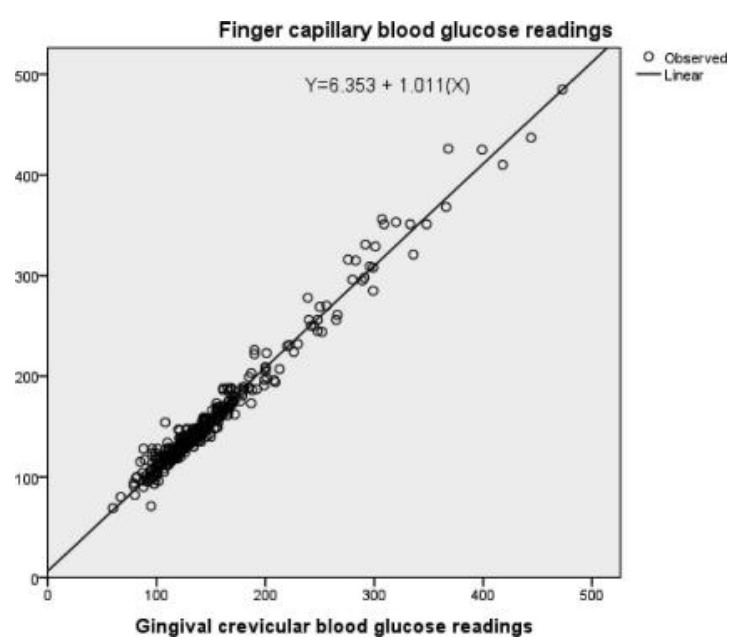

Scatter plot and regression line indicating a linear relationship between $G C B$ and FCB glucose levels. Level of significance $<0.0001$, Correlation Coefficient $(R)=0.987$, Coefficient of determination $\left(R^{2}\right)=0.974$

\section{Figure 4}

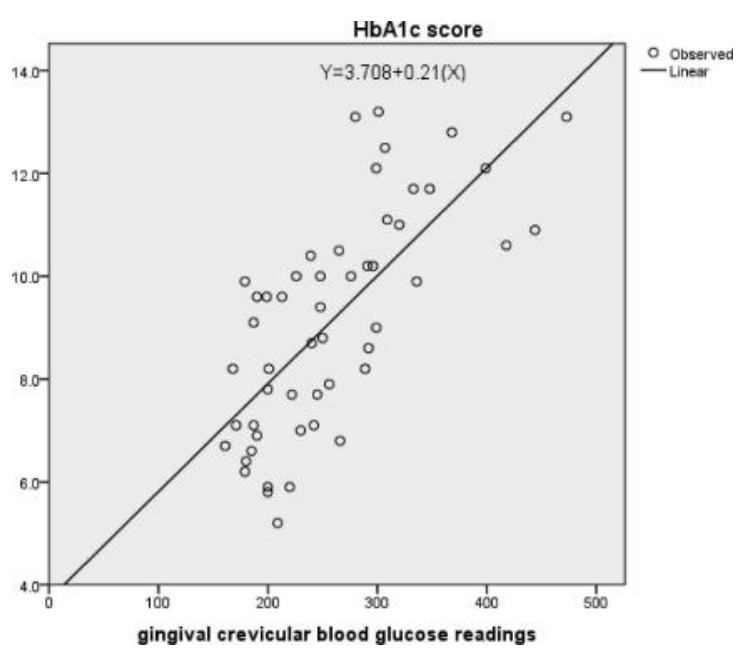

Scatter plot and regression line indicating a linear relationship between GCB and Intravenous HbAlc levels. Level of significance $<0.0001$, Correlation Coefficient $(R)=0.709$, Coefficient of determination $\left(R^{2}\right)=0.502$ 
specificity of GCB glucose testing. The area under the curve was 0.985 (Figure 2) with $94.1 \%$ sensitivity and $100 \%$ specificity at the GCB glucose cut off value of $168 \mathrm{mg} / \mathrm{dl}$.

Regression analysis was performed to determine the linear relationship of gingival crevicular blood glucose with finger capillary glucose and HbA1c levels. GCB glucose showed significant linear relation with FCB glucose ( $\left.\mathrm{R}=0.987, \mathrm{R}^{2}=0.974, \mathrm{p}=0.000\right)$ and HbA1c levels $(\mathrm{R}=0.709$, $\left.\mathrm{R}^{2}=0.502, \mathrm{p}=0.000\right)$. The scatter plots summarize the linear relationshipof GCB with FCB and HbA1c (Figure 3, 4).

\section{DISCUSSION}

Diabetes and periodontitis share a mutual pathological relationship. Periodontally diseased patients are more susceptible to diabetes and many patients visiting the dental office may have undiagnosed asymptomatic diabetes. ${ }^{6}$ Majority of patients visiting dental practitioners may have never been screened for diabetes. Blood glucose evaluation at a dental visit may provide a good opportunity for screening of diabetes in periodontitis patients. Gingival bleeding upon probing is one of the most common signs of periodontal inflammation. ${ }^{21}$ In this study, we evaluated the reliability of gingival crevicular blood glucose testing via glucometers in patients with periodontitis and correlated the results with finger capillary blood glucose readings and $\mathrm{HbAlc}$ scores. All the participants recruited for the study agreed to glucose screening via $\mathrm{GCB}$, indicating that the screening technique was acceptable and comfortable for the periodontal patients. Rosedale et al(2012) also reported that screening of diabetes via GCB was non- invasive and convenient for the patients. ${ }^{12}$

To determine the association between GCB and FCB glucose levels, Pearson's correlation was used which showed a significantly strong correlation, indicating that there exists a very strong positive association between the two variables. This strong positive correlation between GCB and FCB suggests that GCB can potentially be used to screen for diabetes in periodontal patients. The present study supports the results of the study carried out by Parker et al(1993), who found significant correlation between GCB and FCB glucose levels. ${ }^{22}$ Jain $\mathrm{S}$ et al(2015) also found strong correlation ( $\mathrm{R}$ $=0.893, \mathrm{p}=0.001)$ between GCB and FCB glucose levels in their study.23 Beikler et al(2002) also proved the usefulness of GCB for glucose assessment in diabetic and non-diabetic patients. ${ }^{24}$

HbA1c test was performed as a confirmatory analysis in patients with high or borderline increased glucose levels. When GCB glucose levels were correlated with $\mathrm{HbA} 1 \mathrm{c}$ scores, significant positive correlation was observed. In this study, GCB glucose showed stronger correlation with FCB glucose levels than HbA1c as both GCB and FCB showed point in time random capillary blood glucose levels as compared to $\mathrm{HbA} 1 \mathrm{c}$ which showed the 3 monthly glycemic record of the patient. The mean GCB glucose levels were generally found to be lower than FCB glucose levels. The possible reason could be dilution of GCB sample with gingival crevicular fluid and saliva, which have lower glucose levels than blood. When the means of GCB and FCB were compared, significant difference was observed indicating that GCB and FCB glucose levels were related but not similar. These findings are in accordance with the results of the study carried out by Muller et al and Debnath et al who found significant difference in mean between GCB and FCB values. ${ }^{16,17}$ Difference in mean between the two variables indicated that GCB cannot be used as a substitute for FCB for glucose assessment at the same cut-off values.

However, the high sensitivity and specificity of this method indicate that GCB glucose screening can be reliably carried out for screening diabetes with a cut-off value of $168 \mathrm{mg} / \mathrm{dl}$. The role of GCB for the study carried out by Parihar S et al(2016) also showed high sensitivity (100\%) and specificity $(98.4 \%)$ of GCB glucose screening via glucometers. ${ }^{25}$

The linear regression analysis demonstrated that gingival crevicular blood glucose values can significantly predict finger capillary blood glucose values $(\mathrm{R} 2=0.987$, $\mathrm{p}<0.0001)$ which is in agreement with the results of the linear regression between GCB and FCB glucose $\left(\mathrm{R}^{2}=0.954\right.$, $\mathrm{p}=<0.001)$ observed by Gaikwad et al(2013). ${ }^{26}$ Similar results were obtained by Shetty et al in their study. ${ }^{27}$ Linear regression analysis between GCB glucose levels $\mathrm{HbA} 1 \mathrm{c}$ scores revealed significant linear association $\left(\mathrm{R}^{2}=0.502\right.$, $\mathrm{p}<0.0001)$ between the two suggesting that GCB glucose is a good predictor of HbA1c scores. High GCB glucose levels can give an indication of underlying uncontrolled diabetes and may be a first clue to asymptomatic undiagnosed diabetes in periodontally diseased patients visiting dental practitioners. ${ }^{28}$ Therefore, GCB glucose assessment at a dental visit serves as an important screening opportunity for the periodontal patients who are at risk of diabetes. As treatment of periodontitis requires multiple visits to the dentist, blood glucose readings can be recorded in known diabetics to evaluate their glucose control as the treatment advances.Aside from this, suspected diabetics can likewise be screened in the dental office itself and afterward referred for further examinations whenever required. Since the estimation of glucose through GCB includes a speedy and straightforward intraoral methodology with negligible cost, dental experts might be persuaded to execute diabetes screening in future. To the best of our knowledge, this was the first study to conclude that random GCB glucose levels are strongly correlated with Hbalc values and GCB glucose 
levels can predict Hba1c score of the patients with periodontitis.

\section{CONCLUSION}

Gingival crevicular blood glucose assessment is a reliable method to screen blood glucose levels in periodontal patients at a cut-off value of $168 \mathrm{mg} / \mathrm{dl}$. Efforts should be made to reinforce the screening of diabetes in dental setups as the procedure has proved to be acceptable for the patients. It is recommended that dental practitioners and staff should be trained to carry out diabetes screening of periodontal patients at the dental office.

\section{CONFLICT OF INTEREST}

None declared

\section{FUNDING}

The study was self-funded by the researcher Disclaimer:This original article is a component of the research study called "Clinicopathological correlation of disease severity in periodontitis with crevicular blood glucose estimation".

\section{REFERENCES}

1. Preshaw PM, Alba AL, Herrera D, et al. Periodontitis and diabetes: a two-way relationship. Diabetologia. 2012;55:21-31 https://doi.org/10.1007/s00125-011-2342-y

2. Llambés F, Arias-Herrera S, Caffesse R. Relationship between diabetes and periodontal infection. World J. Diabetes. 2015;6:92735 .

https://doi.org/10.4239/wjd.v6.i7.927

3. Beagley J, Guariguata L, Weil C, Motala AA. Global estimates of undiagnosed diabetes in adults. Diabetes Res Clin Pract 2014;103:15060 .

https://doi.org/10.1016/j.diabres.2013.11.001

4. Meo SA, Zia I, Bukhari IA, Arain SA. Type 2 diabetes mellitus in Pakistan: Current prevalence and future forecast. J Pak Med Assoc. 2016;66:1637-42.

5. American Diabetes Association. Standards of medical care in diabetes-2016: Summary of Revisions. Diabetes Care. 2016; 39 (Suppl. 1):S4-S5.

https://doi.org/10.2337/dc16-S003

6. Teeuw WJ, Kosho MF, Poland CW, Gerdes EA, Loos BG. Periodontitis as a possible early sign of diabetes mellitus. Diabetes Res Care. 2017;5(1):e000326.

https://doi.org/10.1136/bmjdrc-2016-000326
7. American Diabetes Association. Diagnosis and classification of diabetes mellitus. J Diabetes Care. 2014; 37( Suppl.1):S81-S90. https://doi.org/10.2337/dc14-S081

8. Heinemann L, Lodwig V, Freckmann G. Accuracy in blood glucose measurement: what will a tightening of requirements yield? J Diabetes Sci Technol. 2012;6:435-443.

https://doi.org/10.1177/193229681200600232

9. Kaur H, Singh B, Sharma A. Assessment of Blood Glucose Using Gingival Crevicular Blood in Diabetic and Non-Diabetic Patients: A Chair Side Method. J Clin Diag Res. 2013;7:3066-9.

10. Tsutsui P, Rich SK, Schonfeld SE. Reliability of intraoral blood for diabetes screening. J Oral Med. 1985;40:62-6.

11. Rajesh KS, Irshana R, Arun Kumar MS, Hegde S. Effectiveness of glucometer in screening diabetes mellitus using gingival crevicular blood. Contemp. Clin Dent. 2016;7:182-185.

https://doi.org/10.4103/0976-237X.183072

12. Rosedale MT, Strauss SM. Diabetes screening at the periodontal visit: patient and provider experiences with two screening approaches. In.t J Dent Hyg. 2012;10:250-258.

https://doi.org/10.1111/j.1601-5037.2011.00542.x

13. Chapple ILC, Genco R. Diabetes and periodontal diseases: consensus report of the Joint EFP/AAP Workshop on Periodontitis and Systemic Diseases. J. Clin Periodontol. 2013;40:S106-S112.

https://doi.org/10.1111/jcpe.12077

14. Gupta A, Gupta N, Garg R, Jain N, Atreja G, Walia SS. Developing a chair side, safe and non-invasive procedure for assessment of blood glucose level using gingival crevicular bleeding in dental clinics. J Nat Sci Biol Med. 2014;5:329-332.

https://doi.org/10.4103/0976-9668.136177

15. Banerjee S, Ganguly R, Pal TK. Gingival crevicular blood: A noninvasive pathway to determine blood glucose level in periodontal patients. Indian J Dent Sci 2017;9:220-4

https://doi.org/10.4103/IJDS.IJDS_88_17

16. Muller HP, Behbehani E. Screening of elevated glucose levels in gingival crevice blood using a novel, sensitive self-monitoring device. Med Princ Pract. 2004;13:361-5.

https://doi.org/10.1159/000080474

17. Debnath P, Govila V, Sharma M, Sainy A, Pandey S. Glucometric assessment of gingival crevicular blood in diabetic and non-diabetic patients: A randomized clinical trial. J Oral Biol Craniofac Res. 2015; 5:2-6.

https://doi.org/10.1016/j.jobcr.2014.12.004

18. Bokhari SAH, Sohail AM., Imran MF. Periodontal disease status and associated risk factors in patients attending a dental teaching hospital in Rawalpindi,Pakistan. J Indian Soc Periodontol. 2015;19:67882.

https://doi.org/10.4103/0972-124X.156882

19. American Diabetes Association. Diagnosis and Classification of 
Diabetes Mellitus. Diabetes Care. 2010; 33(Suppl.1):s62-s9. https://doi.org/10.2337/dc10-S062

20. American Diabetes Association. Standards of medical care in diabetes. Diabetes Care. 2013; 36(Suppl.1):11-66.

https://doi.org/10.2337/dc13-S011

21. Lang NP. Bartold PM. Periodontal Health. J Periodontol. 2018; 89:s9-s16.

https://doi.org/10.1002/JPER.16-0517

22. Parker RC, Rapley JW, Isley W, Spencer P, Killoy WJ. Gingival crevicular blood for assessment of blood glucose in diabetic patients. J Periodontol. 1993;64:666-72.

https://doi.org/10.1902/jop.1993.64.7.666

23 Jain S, Shashikanth MC, Sur J, Khan F, Mujoo S, Dewangan D. Correlation of blood glucose level in gingival crevicular blood and finger capillary blood using glucometer. J Indian Acad Oral Med Radiol 2015;27:338-42

https://doi.org/10.4103/0972-1363.170439

24. Beikler T, Kuczek A, Petersilka G., Flemming TF. In-dental-office screening for diabetes mellitus using gingival crevicular blood. J Clin periodontol. 2002;29:216-8.

https://doi.org/10.1034/j.1600-051x.2002.290306.x

25. Parihar S, Tripathi R, Parihar AV, Samadi FM, Chandra A, Bhavsar $\mathrm{N}$. Estimation of gingival crevicular blood glucose level for the screening of diabetes mellitus: A simple yet reliable method. J Oral Biol Craniofac Res. 2016;6:198-203.

https://doi.org/10.1016/j.jobcr.2016.05.004

26. Gaikwad S, Jadhav V, Gaurab A, Shete A.R, Dearda HM. Screening of diabetes mellitus using gingival crevicular blood with the help of a self-monitoring device. J Periodontal Implant Sci. 2013;43:37-40. https://doi.org/10.5051/jpis.2013.43.1.37

27. Shetty N, Shankarapillai R, Mathur LK, Manohar B, Mathur A, Jain M. Gingival crevicular blood: As a non-invasive screening tool for diabetes mellitus in dental clinics. J Indian Soc Periodontol. 2013; $17: 472-7$.

https://doi.org/10.4103/0972-124X.118319

28. Genco SR, Dunford R, Falkner K., Hsu W, Balukjian J. Screening for diabetes mellitus in dental practices A field trial. J Am Dent Assoc. 2014;145:57-64.

https://doi.org/10.14219/jada.2013.7 